\title{
Educational technology - A recipe for change?
}

\author{
Colin R. Latchem \\ Educational Media Centre \\ Western Australian Institute of Technology
}

\begin{abstract}
While not everyone shares the same perception of what educational technology is, the past two decades have witnessed the implementation of many technological and educational changes which have been to some degree stimulated by educational technologists in their diverse roles. Future progress is more likely to be dependent upon attitudinal change and political will than technical advancement and there is a growing awareness of a need for an Australian Council for Educational Technology. Such a Council could develop information and contact networks between existing agencies and production and delivery consortia which transcended institutional or State boundaries and served cross-sectoral needs.
\end{abstract}

Some readers may be familiar with the stories about the Mulla Nasrudin which illustrate the Sufi school of philosophy. In one of these, Nasrudin was brought to trial accused of seeking to undermine the State by accusing its wise men of being ignorant, irresolute and confused. Before sentence, he was granted a final request and he asked that each of his judges should be separately required to write down their answer to the question "What is bread?" When the answers were read out in court, one judge had defined bread as "that which sustains us"; the second had defined it as "flour and water"; the third as "a gift of Allah"; the fourth as "baked dough" and the fifth as "it depends what you mean by bread". Nasrudin then appealed, saying "How can you entrust such matters of judgement to these wise men? They can't agree about something they eat every day and yet, when it comes to me, they can be unanimous in their verdict that I am a heretic".

I am reminded of this story when I hear or read that educational technology has been a failure or is an alien concept to many educators. Harry Kay (1979) in his presidential address to the UK Association for 
Educational and Training Technology (AETT) said, "I wish, as a ViceChancellor, I could tell you that every time the subject of educational technology is mentioned, a warm glow of sympathy and support circulates throughout Senate chambers. Alas it does not. We still hear, as one academic put it "I have never felt the need for advice on how to teach".

One suspects that another might say, "I don't accept behaviourism as an adequate model of learning"; another, "I can't and won't be replaced by gadgetry"; another "It always costs money and we can't afford it"; another, "it is not an exact science", and another, "it depends what you mean by educational technology". From such attitudes, predilections and prejudices, it is clear that many of our fellow educators do not yet share our enthusiasm for, or commitment to, educational technology, or even hold a common view of what it is. Of course, it could be because educational technology is like Nasrudin - indefinable and therefore indestructible; but I would surmise that our particular history has also been a contributing factor.

Two decades or so ago, educational technology was, albeit somewhat uneasily, an alliance of AV, behaviourism, programmed learning and the systems approach. Technical developments such as CCTV and teaching machines were heralded as opening up a new era of educational effectiveness, efficiency and opportunity. When it transpired that this was a false dawn, we denied that the field was wholly tools dependent, explaining that the term 'technology' implied a systems approach rather than technical products. Now, with rapid advances in computing, video and telecommunications, all with interactive capabilities, there is renewed confidence in the technical products. Educational technologists are once again predicting the radicalisation of the classroom and the progressive deinstitutionalisation of education.

Experience teaches us to be cautious about such claims - or, at least, the time scale in which major systems change will come about. Educational technology can obviously make good use of these powerful new technologies as well as the older non-electronic ways of gathering, transforming and transmitting information. However, it is the transformation of information - the availability or production of appropriate software in any medium - that is one of the major problems associated with changing educational processes. Essentially, educational technology seeks to develop knowledge, skills and successful practices through problem-oriented research and development and uses all available systems, methods and media to help advance: 
- curriculum and instructional design;

- training and professional development;

- teaching and learning techniques and strategies;

- computer-assisted, computer-based and computer-managed learning;

- open learning, informal learning and distance education;

- resource-based learning and resource management;

- applications of $\mathrm{AV}$, information and communications technology;

- research and evaluation;

- theoretical studies in educational technology;

or any combination of these.

Many of these activities and applications are not the exclusive domain of educational technology and the list is not exhaustive, but it serves to explain why educational technology sometimes functions under other nomenclatures (eg. media, educational development, or computer services) and to show that some tasks are highly tools-dependent while others are not. The list also reminds us of how far we have travelled in two decades or so. Like other educators and managers of change, educational technologists have often lacked clear theoretical guidance (or even clear policy guidelines from 'above') but their knowledge and skills and partnerships with subject and other experts have contributed to changes in the art and science of education. Like Nasrudin, the educational technologist's role has been constantly changing - sometimes it has been that of the fool and sometimes that of the sage, the courtier, the beggar, the physician, the judge, the teacher or the learner. The list also reminds us that needs may be convergent so that the educational technologist may have to seek methods, systems and / or learning packages that are suited to the classroom and to distance learning, or to education and to training; and sometimes the technology is convergent so that the educational technologist has to acquire new skills or assemble new teams to achieve the expertise needed, for example in developing interactive AV and data systems for satellite-delivered education.

So rapidly has the technology advanced, so 'user friendly' and, at least until the recent fall of our dollar, so progressively cheaper has it become, that now at least, in principle, we can say to our teachers - "Everything is now technically possible - how much do you want to change?" And to our researchers we can say, "Everything is now technically possible - what more can you tell us about how people learn and are motivated to learn?" And to our governments and institutions we can say, "Everything is now technically possible - what changes do you want to make in the present system and what alternative systems do you need?" In the current economic climate, finding the answers to these questions will inevitably be made harder - or more necessary - according to the political will of the country. 
Kay warns that "the defence mechanisms (in education) are as impregnable as the walls of Troy - you will only get inside by a combination of skill, sympathy and subtlety". Roach (1985) observes that to date in the UK, CAL and interactive video have failed to stimulate a flood of interest among the majority of teachers or a rush to convert the classrooms into resource centres. He finds that these learning systems, so capable of dialogue with the students, are more typically used initially as teaching aids, obedient servants to the teachers' commands. From this 'gentle act of self-defence', an inevitable part of the lengthy adapt-adopt process of any change, we see the need to convince teachers that the new learning systems have the potential to free them of some of the burdens of instruction and to help them achieve more in the same time, or as much in a shorter period of time. Any perceived threat to the teachers' professional esteem, or worse still, their jobs, will only impede progress.

Politically, we may find it more fruitful to concentrate more of our efforts on using new systems, methodologies and technologies to create new forms of educational opportunity, hoping that these innovations will then feed back into the current system, rather than continually trying to tackle the current systems head on.

We cannot of course ignore the capital, consumable and labour costs of any magnitude of change. Maggs and Ray (1985) predict microcomputers becoming as numerous as overhead projectors and photocopiers in Australian schools, but this falls far short of the degree of technical penetration required for any major systems change. Nor can Peter be always robbed to pay Paul. There is evidence (Bates, 1985) that there is a worldwide trend of funding 'newer technologies' (eg. computers) at the cost of 'older technologies' with well-proven applications (eg. video). Such budgetary decisions endanger the educational technology principle of identifying and selecting the medium or media most appropriate to the task, the learner and the context; and all of these media need adequate supplies of acquired or specially produced "software' or 'courseware'. Unwin (1981), Dede (1981) and Brong (1981) predict that the economics of scale in software production may well lead to dominance by American or multinational producers and that while this software may be of a high quality, it is most likely to be prescriptive, "perennial., broad-based and standardised. Such materials would clearly make little or no allowance for curricular, pedagogical and cultural differences in Australia, so there is obviously a need for production consortia to be developed to meet our domestic needs and hopefully, to market materials overseas. 
In considering these issues, it has to be noted that in those developed and developing countries that have sought to make major uses of educational, information and communications technology to enhance and extend learning - for example, in Canada, where satellite- delivered 'telecourses' are offered to thousands of students through such systems as the British Columbia Knowledge Network of the West (KNOW), in the UK with its Open University, 'Open Tech' and Microelectronics Education Programme (MEP), and in countries such as China and India, where broadcast television issued for community education on an unprecedented scale central government has perceived the economic and social advantages of, and has had a key role in, change. In Australia, as Maggs and Ray (1985) observe, there is no central coordinated pattern or policy governing direction, implementation or enhancement of education, let alone educational technology, at the national scale.

I detect a growing awareness of the need for an Australian Council for Educational Technology. Such a body would be separate from government, but would advise government and work as an 'enabling organisation' with the various educational, industrial and government agencies to encourage and support educational technology for education and training in a time of economic stringency. Such a Council could address the issues addressed in 'Education and Technology' (1985). Its secretariat could help to develop information and contact networks and production consortia which transcended State and sectoral boundaries. It could work through the agency of existing institutions, training organisations, broadcasters, telecommunications and other providers, helping to develop priorities, centres of excellence, task sharing and resource sharing in order to achieve the structural changes required for effective and cost beneficial communications and teaching and learning delivery systems.

If a country wants to demonstrate the capabilities of information technology in a dramatic way it may need to initiate a major national project that is universally useful, captures the public's imagination and stimulates maximum cooperation and participation - an undertaking such as the UK interactive video 'Domesday Project' described by Atkins (1985). This ambitious project, a comprehensive record of life in the UK in the twentieth century, was funded by the Department of Trade and Industry (DTI) and developed by the BBC, Open University, Philips Electronics, Acorn Computers and various government and other research organisations, including the project's own unique 'people's data tease' of $1,000,000$ people from 13,000 schools and 1,000 community groups throughout the country. The combined data and audiovisual applications 
of the 'Domesday Project' demonstrate the capabilities of the new resources we have at our disposal for information gathering, information transformation, information transfer and the democratisation of knowledge.

To finish on an optimistic note, I recently had a 'sneak preview' of the interactive video programme designed to help pupils in their choice of career which has been developed by the Australian Caption Centre with some help from the Audio Visual Education Branch of the Education Department of Western Australia. The project was created by a team from different disciplines, different institutions and even different States. It is an impressive achievement and a landmark in what can be achieved by Australian educational technologists when they are 'given a fair go'.

Given the political will, and possibly with the establishment of an Australian Council for Educational Technology to maintain the momentum of such projects, Australian educational technology could still be among the world's leaders.

\section{References}

Arnold, L.M.F. (Chairperson). (1986). Education and Technology: Report of the Australian Education Task Force on Education and Technology. Melbourne: Australian Education Council.

Atkins, S. (1985). The Domesday Project. Media in Educational Development, 18(3), 110-113.

Bates, T. (1985). Chairman's Notes. Educational Television Association News, $35,2$.

Brong, G.R. (1981). Multinational Corporations and Learning Resources Reduction of Content to the Lowest Common Denominator. Programmed Learning and Educational Technology, 18(4), 262-270.

Dede, C. (1981). Educational, Social and Ethical Implications of Technological Innovation. Programmed Learning and Educational Technology, 18(4), 204-213.

Kay, H. (1979). Keynote address. Educational technology 20 years on Sheffield revisited. In G.T. Page and Q. Whitlock (eds), Aspects of Educational Technology XIII - Educational Technology Twenty Years On. London: Kogan Page, pp11-18.

Maggs, A. \& Ray, E. (1985). Microcomputers and education. Australian Journal of Educational Technology, 1(1), 2-11.

http: / / www.ascilite.org.au/ajet/ajet1/maggs.html 
Roach, K (1986). Editorial. The Gentle Art of Self-defence. Journal of Educational Television, 11(3), 157-158.

Unwin, D. (1981). The Future Direction of Education Technology. Programmed Learning and Educational Technology, 18(4), 204-213.

Please cite as: Latchem, C. R. (1986). Educational technology - A recipe for change? Australian Journal of Educational Technology, 2(1), 5-11.

http://www.ascilite.org.au/ajet/ajet2/latchem.html 